\title{
INTERFERÊNCIA DE Brachiaria plantaginea COM A CULTURA DO ARroz, CV. Primavera
}

\author{
Weed Competition Between Brachiaria plantaginea and Rice Culture, $\mathrm{cv}$. \\ 'Primavera' \\ VELHO, G.F. ${ }^{3}$, CRUSCIOL, C.A.C. ${ }^{2}$, VELINI, E.D. ${ }^{6}$, CASTRO, G.S.A. ${ }^{5}$ e \\ BORGHI, E. ${ }^{4}$
}

\begin{abstract}
RESUMO - O objetivo deste trabalho foi avaliar os efeitos da interferência de Brachiaria plantaginea, em diferentes densidades e períodos de convivência, nos componentes de produção e produtividade de grãos de arroz. O experimento foi instalado no município de Santo Antônio de Posse - SP em delineamento de blocos ao acaso, com seis repetições, em esquema fatorial $7 \times 4$. Os tratamentos consistiram de sete períodos de convivência, expressos em dias após a emergência das plântulas (DAE) de B. plantaginea: controle - O DAE, 7 DAE, 14 DAE, 21 DAE, $28 \mathrm{DAE}, 35 \mathrm{DAE}$ e sem controle das plantas daninhas, combinados com quatro densidades dessas plantas: 1, 5, 25 e 90 plantas $\mathrm{m}^{-2}$. Foi avaliada a produção de massa seca de B. plantaginea, além dos componentes da produção e produtividade de grãos do arroz. O acúmulo de massa seca de $B$. plantaginea aumentou significativamente em todas as densidades com o aumento do período de convivência. O aumento do período de convivência e da densidade de plantas de $B$. plantaginea ocasionou redução dos componentes da produção e, consequentemente, da produtividade de grãos de arroz.
\end{abstract}

Palavras-chave: Oryza sativa, capim-marmelada, períodos de convivência, densidade de plantas daninhas.

\begin{abstract}
The objective of this work was to evaluate the effects of interference of Brachiaria plantaginea at different densities and control periods in rice yield components and grain yield. The experiment was conducted in Santo Antônio de Posse-SP, Brazil, in a completely randomized block design, with six replications, in a $7 \times 4$ factorial. Treatments consisted of seven control periods, expressed in days after B. plantaginea emergence (DAE): Control - O DAE; $7 D A E$, $14 \mathrm{DAE} ; 21 \mathrm{DAE} ; 28 \mathrm{DAE}, 35 \mathrm{DAE}$, and without weed control, combined with four weed densities: 1, 5, 25 and 90 plants $\mathrm{m}^{-2}$. B. plantaginea dry matter and rice yield components and grain yield were evaluated. Dry matter production of $\boldsymbol{B}$. plantaginea increased significantly as the control period was delayed, at all weed densities. Increasing control periods and weed densities decreased rice yield components and, consequently, grain yield. Amongst other factors, the interference of B. plantaginea in rice depends on its density and period of coexistence.
\end{abstract}

Keywords: Oryza sativa, alexandergrass, control periods, weed density.

1 Recebido para publicação em 17.3.2011 e aprovado em 26.9.2011.

Parte da tese de doutorado do segundo autor.

2 Pesquisador, BASF S/A, Estação Experimental Agrícola Rodovia SP 340 - Km 144, Santo Antônio de Posse-SP, < gilberto-fernando.velho@basf.com>; ${ }^{3}$ Professor Titular, Dep. de Produção Vegetal, Faculdade de Ciências Agronômicas, Universidade Estadual Paulista - FCA/UNESP, Campus de Botucatu, Caixa Postal 237, 18603-970 Botucatu-SP, Bolsista do CNPq, <crusciol@fca.unesp.br>; ${ }^{4}$ Professor Adjunto, Dep. de Produção Vegetal, FCA/UNESP, Campus de Botucatu, Bolsista do CNPq, <velini@fca.unesp.br>, ${ }^{5}$ Doutorando em Agronomia - Agricultura, Dep. de Produção Vegetal, FCA/UNESP, Bolsista FAPESP, <gsacastro@hotmail.com>; ${ }^{6}$ Pesquisador, EMBRAPA Pesca e Aquicultura, Quadra 103 Sul, Avenida JK, ACSO 01, Conjunto 01, Lote 17, Térreo, Plano Diretor Sul, 77015-012 Palmas-TO, <emerson.borghi@yahoo.com.br>.

Planta Daninha, Viçosa-MG, v. 30, n. 1, p. 17-26, 2012 


\section{INTRODUÇÃO}

O arroz ocupa posição privilegiada no cenário agrícola, pois está presente na dieta básica da maioria dos brasileiros. A área cultivada no Brasil na safra 2009/2010 representou aproximadamente 2,758 milhões de hectares, com produção de 11,24 milhões de toneladas e rendimento médio de $4.073 \mathrm{~kg} \mathrm{ha}{ }^{-1}$, contabilizando os ecossistemas de cultivo de arroz irrigado e de terras altas (CONAB, 2011).

Existem vários fatores limitantes na produtividade do arroz, entre os quais destaca-se a matointerferência, por meio da competição por água, luz e nutrientes. As plantas daninhas também limitam a produtividade por meio de ações indiretas, como hospedeiras de pragas e doenças, e, ainda, muitas vezes, por seus efeitos alelopáticos, podendo causar perdas na cultura do arroz entre 52 e 100\% (Fleck et al., 2008; Silva \& Durigan, 2009). Para Radosevich et al. (1997), a densidade de plantas daninhas é a característica vegetal que mais afeta a interferência sobre as culturas de interesse agronômico.

Estima-se que a produção mundial de arroz sofra reduções significativas pela ação das plantas daninhas, pragas e patógenos, chegando à ordem de 35, 24 e 16\%, respectivamente (Oerkr \& Dehne, 2004).

As dimensões dos efeitos negativos da matointerferência sobre a produtividade são diversas e dependem de vários fatores, como o cultivar de arroz utilizado, a fertilidade do solo, a adubação empregada, a densidade e espaçamento da cultura e as plantas daninhas presentes - em especial, a espécie e seu período de convivência com a cultura do arroz (Christoffoleti \& Passini, 1999).

Entre as plantas daninhas encontradas na cultura do arroz de terras altas, nas diversas regiões produtoras do Brasil, sem dúvida uma das mais importantes e agressivas é B. plantaginea, conhecida popularmente como capim-marmelada. Essa planta daninha se destaca por ser de ocorrência bastante frequente e por sua alta agressividade, podendo acarretar elevados prejuízos para a produção das mais diversas culturas. Esses prejuízos variam conforme o estádio de desenvolvimento, o ciclo da cultura, bem como com a duração do período de interferência.
Dessa forma, para diminuir ao máximo a interferência das plantas daninhas na produtividade do arroz, a cultura deverá permanecer livre de plantas daninhas até 30 DAE. Pelo fato de a maioria dos cultivares modernos apresentar baixa taxa de crescimento inicial e menor porte que os de cultivares tradicionais, uma cobertura adequada do solo pelas plantas só ocorre aos 40-50 dias após a semeadura (Silva \& Durigan, 2009).

Estudos sobre competitividade de culturas com plantas daninhas permitem desenvolver estratégias para seu manejo. Recentemente, pesquisas foram intensificadas e direcionadas para definir características que confiram maior habilidade competitiva, principalmente nas culturas de arroz e trigo e, em menor proporção, de milho e soja (Fleck et al., 2008).

Por muito tempo não foi dada importância ao controle de plantas daninhas em arroz de terras altas, por ter sido este cultivado, quase sempre, em áreas recém-desbravadas, ainda livres de plantas daninhas, sem necessidade de medidas de controle. Em consequência, há, atualmente, carência de produtos e tecnologia para o controle de plantas daninhas na cultura de arroz nesse ecossistema (Silva \& Durigan, 2009). Essa carência é agravada pela baixa capacidade de competição do arroz com plantas daninhas, em relação a outras culturas, o que representa, no momento, um dos principais obstáculos para a introdução da cultura do arroz de terras altas em sistemas agrícolas permanentes.

Portanto, este trabalho teve como objetivo avaliar o efeito da matointerferência de B. plantaginea, em diferentes densidades e periodos de convivência com a cultura do arroz, através da avaliação de seus componentes de produção e produtividade de grãos.

\section{MATERIAL E MÉTODOS}

O trabalho foi instalado e conduzido na Estação Experimental Agrícola da BASF S.A., Sítio São João do Quinhão, município de Santo Antônio de Posse - SP, cujas coordenadas geográficas são $47^{\circ} 04^{\prime}$ de longitude oeste e $22^{\circ}$ 53 ' de latitude sul, com altitude de $696 \mathrm{~m}$. O solo do local é um Latossolo Vermelho, textura argilosa (Embrapa, 2006). A precipitação pluvial média anual é de aproximadamente 
$1.310 \mathrm{~mm}$, a temperatura média anual está ao redor de $22,7^{\circ} \mathrm{C}$ e a umidade relativa do ar, entre 50 e 92\% (variação anual). A área apresentava sistema de irrigação por aspersão. A precipitação pluvial $(\mathrm{mm})$ e as temperaturas máxima e mínima $\left({ }^{\circ} \mathrm{C}\right)$ registradas no ano agrícola 1999-2000 constam na Figura 1.

O delineamento experimental utilizado foi o de blocos ao acaso, em esquema fatorial simples $7 \times 4$, sendo constituído por sete períodos de convivência, em dias após a emergência (DAE) de B. plantaginea: 1- controle (sem interferência) - 0 DAE, 2 - 7 DAE, 3 - 14 DAE, 4 - 21 DAE, 5 - 28 DAE, 6 - 35 DAE e 7 - com planta daninha durante todo o ciclo da cultura (100 DAE), combinados com quatro densidades da planta daninha: $\mathrm{D} 1=1$ planta $\mathrm{m}^{-2}, \mathrm{D} 2=$ 5 plantas $\mathrm{m}^{-2}$, D3 -25 plantas $\mathrm{m}^{-2}$ e $\mathrm{D} 4=$ 90 plantas $\mathrm{m}^{-2}$, com seis repetições.

Cada unidade experimental foi constituída por sete fileiras de plantas de arroz com $7 \mathrm{~m}$ de comprimento cada, espaçadas de 0,40 m. Foram consideradas como área útil as cinco fileiras centrais; $0,50 \mathrm{~m}$ da extremidade de cada fileira de plantas e as duas fileiras externas constituíram-se na bordadura. $\mathrm{O}$ cultivar de arroz utilizado foi o Primavera, e a espécie daninha semeada foi $B$. plantaginea, conhecida regionalmente como capim-marmelada (Voll et al., 1995; Theisen et al., 2000).

Antes da instalação do experimento, foram coletadas amostras de solo da área experimental e realizadas as análises químicas, segundo metodologia proposta por Raij \& Quaggio (1983), na profundidade de 0-0,20 m. Os resultados revelaram as seguintes características: $\mathrm{pH}\left(\mathrm{CaCl}_{2}\right)=5,4 ; \mathrm{MO}=22 \mathrm{~g} \mathrm{~kg}^{-1}$; $\mathrm{P}$ (resina) $=8,3 \mathrm{mg} \mathrm{dm}^{-3} ; \mathrm{K}, \mathrm{Ca}, \mathrm{Mg}$ e $\mathrm{H}+\mathrm{Al}=$ 4,3, 46, 12 e $28 \mathrm{mmol}_{\mathrm{c}} \mathrm{dm}^{-3}$, respectivamente; e saturação por bases de $69 \%$. O solo tinha a seguinte composição granulométrica: $12 \%$ de areia, $24 \%$ de silte e $50 \%$ de argila.

O solo foi preparado mediante preparo convencional contendo uma aração e duas gradagens, sendo a primeira gradagem realizada após a aração e a segunda, às vésperas da semeadura. A adubação de semeadura constou da aplicação nos sulcos de $10 \mathrm{~kg}$ de N, $50 \mathrm{~kg}$ de $\mathrm{P}_{2} \mathrm{O}_{5}$ e $0 \mathrm{~kg}$ de $\mathrm{K}_{2} \mathrm{O}$ ha $^{-1}$. A adubação de cobertura foi realizada 30 dias após a emergência das plantas de arroz, utilizando-se $50 \mathrm{~kg} \mathrm{ha}^{-1}$ de $\mathrm{N}$ na forma de sulfato de amônio.

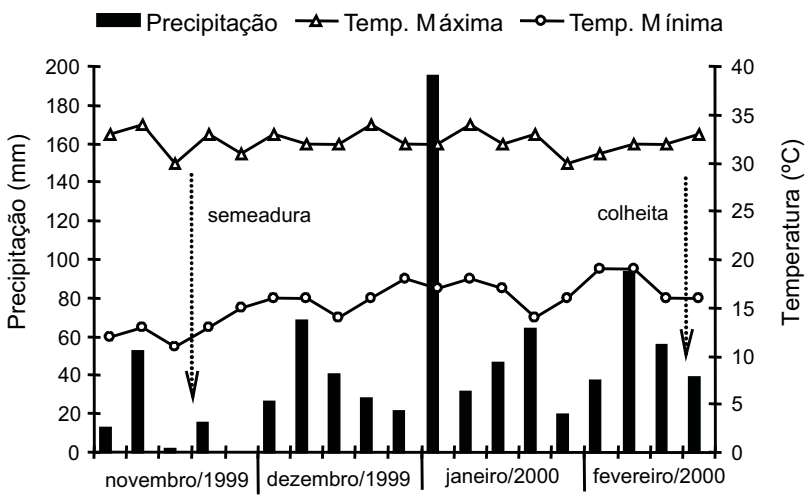

Figura 1 - Precipitação pluvial (mm) e temperaturas máxima e mínima $\left({ }^{\circ} \mathrm{C}\right)$ registradas no ano agrícola 1999-2000. Santo Antônio da Posse-SP.

A semeadura do arroz foi realizada no dia 20/11/1999, utilizando-se a densidade de 150 sementes viáveis por metro quadrado. As sementes foram tratadas com $1,5 \mathrm{~kg} \mathrm{ha}^{-1}$ de carbofuran $5 \mathrm{G}$. A emergência das plântulas ocorreu seis dias após a semeadura, em 26/11/1999.

As sementes de $B$. plantaginea foram obtidas durante o mês de fevereiro de 1998 no município de Santo Antônio da Posse-SP, sendo coletadas na superficie do solo, por meio de varredura, e posteriormente submetidas ao processo de limpeza de impurezas; elas foram armazenadas em câmara com umidade e temperatura controladas de $60 \%$ e $4{ }^{\circ} \mathrm{C}$, respectivamente. Para obter uma germinação uniforme, antes da semeadura, as sementes foram imersas em uma solução de nitrato de potássio $\left(\mathrm{KNO}_{3}\right)$ a $0,2 \%$ durante cinco minutos (Brasil, 1992). B. plantaginea foi semeada no mesmo dia da cultura do arroz. A distribuição foi a lanço em área total de cada parcela; posteriormente, realizou-se incorporação com rastelo em diferentes profundidades ( 1 a $3 \mathrm{~cm})$, para simular a germinação em campo.

As irrigações foram realizadas por um sistema de aspersão convencional fixo, utilizando tensiômetros a $15 \mathrm{~cm}$ de profundidade como indicativos para o fornecimento de água. Assim, adotaram-se, para realizar a reposição de água no solo, os valores correspondentes a $-0,033 \mathrm{MPa}$, nas fases vegetativa e de maturação, e -0,025 $\mathrm{MPa}$, na fase reprodutiva.

O período de convivência de $B$. plantaginea dentro de cada tratamento era controlado 
mediante capina manual de toda a unidade experimental. Assim, no tratamento correspondente ao periodo de sete dias, por exemplo, a capina era efetuada no dia subsequente ao determinado (oitavo dia após a emergência de B. plantaginea).

Foram avaliadas as seguintes variáveis: produção de massa seca de $B$. plantaginea (coleta das plantas em cada época de capina em 1,0 $\mathrm{m}^{2}$ dentro de cada unidade experimental); número de colmos (contagem dos colmos, no momento da colheita, em 1,0 m de duas fileiras de cada unidade experimental e extrapolado para $\mathrm{m}^{2}$ ); número de panículas total, imaturas e maduras (contagem do número de panículas, no momento da colheita, contidas em 1,0 m de duas fileiras de cada unidade experimental, separando-se as maduras das imaturas, sendo os valores extrapolados para $\mathrm{m}^{-2}$ ); colmos férteis (relação número de panículas maduras $\mathrm{m}^{-2} /$ número de colmos $\mathrm{m}^{-2}$ ); número total de espiguetas por panícula; número de espiguetas granadas e chochas por panícula (contagem do número de espiguetas, granadas e chochas, em 15 panículas por unidade experimental); fertilidade das espiguetas (relação entre o número de espiguetas granadas e o número total de espiguetas por panícula); massa de mil grãos (pesagem de quatro amostras de mil grãos de cada unidade experimental padronizados para o teor de água de $130 \mathrm{~g} \mathrm{~kg}^{-1}$ - base úmida); e produtividade de grãos (efetuada manual e individualmente por unidade experimental, quando os grãos de dois terços superiores das panículas apresentavam-se duros e os do terço inferior, semiduros. Os dados foram padronizados para o teor de água de $130 \mathrm{~g} \mathrm{~kg}^{-1}$, base úmida, e calculados em $\mathrm{kg} \mathrm{ha}^{-1}$ ).

Os dados foram submetidos à análise de variância e ajustados a funções matemáticas com $\mathrm{p}>0,05$ de probabilidade pelo teste $\mathrm{F}$. Quando houve interação entre os fatores, realizou-se desdobramento da interação período de convivência dentro de cada densidade de $B$. plantaginea.

\section{RESULTADOS E DISCUSSÃO}

Mediante os resultados da análise de variância (Tabela 1), constatou-se, com exceção da variável fertilidade das espiguetas e da massa de mil grãos, efeito significativo do fator período de convivência para as demais variáveis. Houve efeito significativo do fator densidade somente para as variáveis: massa seca de $B$. plantaginea, número de colmos, número de panículas maduras e produtividade de grãos. Quanto à interação, não houve efeito significativo somente para número de panículas

Tabela 1 - Valores de F e coeficiente de variação das variáveis: massa seca de B. plantaginea, componentes de produção e produtividade de grãos de arroz, em função do período de convivência e da densidade de plantas de B. plantaginea na cultura do arroz. Santo Antônio de Posse-SP, 2001

\begin{tabular}{|c|c|c|c|c|c|c|}
\hline \multirow{3}{*}{ Tratamento } & \multirow{2}{*}{$\begin{array}{c}\text { Massa seca } \\
\text { B. plantaginea }\end{array}$} & \multicolumn{4}{|c|}{ Número $\mathrm{m}^{-2}$} & \multirow[b]{2}{*}{ Colmos férteis } \\
\hline & & Colmos & Panículas totais & $\begin{array}{l}\text { Panículas } \\
\text { maduras }\end{array}$ & $\begin{array}{l}\text { Panículas } \\
\text { imaturas }\end{array}$ & \\
\hline & \multicolumn{6}{|c|}{ Valor de $\mathrm{F}^{1 /}$} \\
\hline Convivência(C) & $130,76^{* *}$ & $49,16^{* *}$ & $59,63 * *$ & $46,39 * *$ & $5,72 * *$ & $10,18^{* *}$ \\
\hline Densidade (D) & $6,88 * *$ & $12,83^{* *}$ & $1,97^{\mathrm{ns}}$ & $8,03 * *$ & $0,26^{\mathrm{ns}}$ & $1,68^{\mathrm{ns}}$ \\
\hline $\mathrm{C} \times \mathrm{D}$ & $8,17 * *$ & $4,49 * *$ & $1,94^{\mathrm{ns}}$ & $3,42 * *$ & $0,83^{\mathrm{ns}}$ & $1,88^{\mathrm{ns}}$ \\
\hline $\mathrm{CV}(\%)$ & 93,45 & 14,70 & 16,78 & 18,96 & 78,70 & 18,26 \\
\hline \multirow{3}{*}{ Tratamento } & \multicolumn{3}{|c|}{ Número de espiguetas/panícula } & \multirow{2}{*}{$\begin{array}{c}\text { Fertilidade das } \\
\text { espiguetas }\end{array}$} & \multirow{2}{*}{$\begin{array}{c}\text { Massa de } \\
1.000 \text { grãos }\end{array}$} & \multirow{2}{*}{$\begin{array}{c}\text { Produtividade } \\
\text { de grãos }\end{array}$} \\
\hline & total & granadas & chochas & & & \\
\hline & \multicolumn{6}{|c|}{ Valor de $\mathrm{F}^{1 /}$} \\
\hline Convivência(C) & $21,21 * *$ & $11,38 * *$ & $23,56 * *$ & $0,87^{\mathrm{ns}}$ & $1,94^{\mathrm{ns}}$ & $111,92 * *$ \\
\hline Densidade (D) & $1,56^{\mathrm{ns}}$ & $0,76^{\mathrm{ns}}$ & $2,07^{\mathrm{ns}}$ & $0,87^{\mathrm{ns}}$ & $0,97^{\mathrm{ns}}$ & $7,42 * *$ \\
\hline $\mathrm{C} \times \mathrm{D}$ & $2,47 * *$ & $2,12 * *$ & $2,97 * *$ & $2,19 * *$ & $1,09^{\text {ns }}$ & $5,97 * *$ \\
\hline $\mathrm{CV}(\%)$ & 16,86 & 21,27 & 19,52 & 10,97 & 6,70 & 15,25 \\
\hline
\end{tabular}

${ }^{1 /}$ Teste $\mathrm{F}:{ }^{*}$ significativo a $5 \%$; ** significativo a $1 \%$ de probabilidade; ${ }^{\text {ns }}$ não significativo. 
totais $\mathrm{m}^{-2}$, número de panículas imaturas $\mathrm{m}^{-2}$, colmos férteis e massa de mil grãos.

A produção de massa seca de $B$. plantaginea aumentou significativamente em todas as densidades com o aumento do período de convivência. Houve maior produção de massa seca nas densidades intermediárias, chegando acima de 7,5 toneladas ha ${ }^{-1}$ nas densidades de 5 e
25 plantas $\mathrm{m}^{-2}$ e em torno de 3,5 toneladas $\mathrm{ha}^{-1}$ nas densidades de 1 e 90 plantas $\mathrm{m}^{-2}$ (Figura $2 \mathrm{~A})$, decorrente, provavelmente, de um perfilhamento mais intenso de $B$. plantaginea nas densidades intermediárias. Além disso, houve elevada mortalidade das plantas e menor desenvolvimento delas na maior densidade. Ficou evidente que a população de plantas atuou diretamente no acúmulo de massa seca
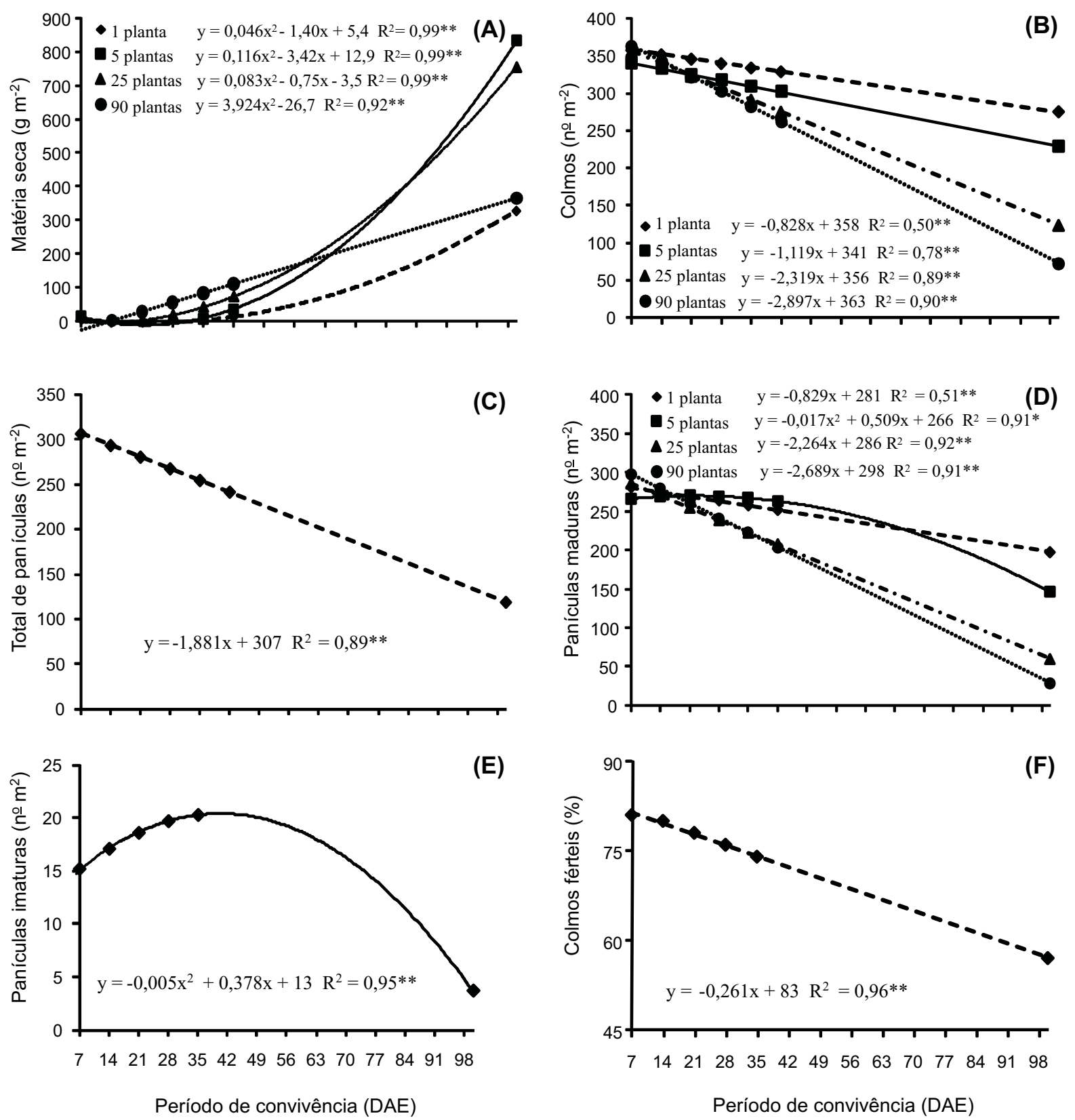

Figura 2 - Massa seca de B. plantaginea (a), número de colmos $\mathrm{m}^{-2}$ (b), número de panículas totais $\mathrm{m}^{-2}$ (c), número de panículas maduras $\mathrm{m}^{-2}(\mathrm{~d})$, número de panículas imaturas $\mathrm{m}^{-2}$ (e) e colmos férteis (f) do arroz de terras altas, em função da densidade de plantas de B. plantaginea e do período de convivência. 
de $B$. plantaginea, com intensidades diferentes nos períodos iniciais, em relação aos finais (Figura 2A). Assim, o incremento da massa seca começa se tornar expressivo a partir de $42 \mathrm{DAE}$, quando há presença de 1 e 5 plantas $\mathrm{m}^{-2}$; $28 \mathrm{DAE}$, quando há 25 plantas $\mathrm{m}^{-2}$; e $21 \mathrm{DAE}$, quando há 90 plantas $\mathrm{m}^{-2}$. No entanto, a intensidade de incremento não foi proporcional à população, e, assim, a presença de 5 e 25 plantas $\mathrm{m}^{-2}$ proporcionou valores muito semelhantes de produção de massa seca, bem como a presença de 1 e 90 plantas $\mathrm{m}^{-2}$ (Figura 2A).

Segundo Radosevich et al. (1997), à medida que aumenta a densidade e ocorre o desenvolvimento das plantas daninhas, intensifica-se a competição inter e intraespecífica, de modo que as plantas daninhas mais altas e desenvolvidas tornam-se dominantes, ao passo que as menores são suprimidas ou morrem. Ainda, segundo Pitelli (1985), em baixas densidades o potencial de interferência de cada indivíduo pode se manifestar com maior intensidade. $\mathrm{Da}$ mesma forma, esse autor ressalta o princípio de Liebig, afirmando que cada indivíduo não poderá crescer de acordo com o seu potencial genético, mas em consonância com as quantidades de recursos que conseguir recrutar, na intensa competição a que está submetido. Dessa forma, em altas densidades, o valor de cada indivíduo como elemento competitivo fica diminuído, e o potencial de crescimento da comunidade é controlado por aquele recurso que, de acordo com as necessidades gerais da comunidade, se apresentar em menor quantidade no ambiente.

O número de colmos foi significativamente reduzido com o período de convivência; a intensidade foi maior com o aumento da densidade da planta daninha (Figura 2B). A competição estabelecida desde o início da convivência, provavelmente, reduziu o número de plantas estabelecidas na área e, posteriormente, por volta dos $20 \mathrm{DAE}$, quando se iniciou o perfilhamento do cultivar, este foi afetado, reduzindo o número de colmos $\mathrm{m}^{-2}$. Fica evidente no presente trabalho que, para essa planta daninha, o período de convivência atua de forma mais intensa na competição com a cultura, nas fases iniciais, do que a população de plantas. Esses resultados corroboram os obtidos por Tozani et al. (1995), que constataram que a comunidade infestante reduziu o perfilhamento do arroz, acarretando menor número de colmos por área. As perdas de produtividade das culturas, em decorrência da competição de plantas daninhas, geralmente aumentam quanto mais semelhantes forem suas características morfofisiológicas (Christoffoleti \& Passini, 1999).

O número de panículas total $\mathrm{m}^{-2}$ foi significativamente reduzido em função do período de convivência, independentemente da densidade de planta daninha (Figura 2C). Essa redução, que chegou a $61 \%$ quando as plantas daninhas conviveram com a cultura do arroz durante todo o ciclo, deveu-se em parte à redução verificada para número de colmos $\mathrm{m}^{-2}$ e, provavelmente, à menor transformação das gemas vegetativas em reprodutivas. Também, as injúrias provocadas pela competição levaram à degeneração do primórdio da panícula, o que explica a redução após $40 \mathrm{DAE}$, ou seja, no início da fase reprodutiva. Um dos efeitos do período de convivência das plantas daninhas com a cultura do arroz, verificado por Tozani et al. (1995), foi a redução do número de panículas $\mathrm{m}^{-2}$. Silva \& Durigan (2009) verificaram que a comunidade infestante reduziu o perfilhamento e o número de panículas de arroz por unidade de área quando a competição ocorreu mais intensamente no final do ciclo da cultura, ou quando foi maior a duração do período de convivência entre as plantas daninhas e a cultura do arroz.

Quanto ao número de panículas maduras $\mathrm{m}^{-2}$ (Figura 2D), verificou-se que nas densidades de 25 e 90 plantas $\mathrm{m}^{-2}$ as reduções foram mais intensas do que nas densidades de 1 e 5 plantas $\mathrm{m}^{-2}$. Para explicar melhor os resultados referentes a panículas totais $\mathrm{m}^{-2}$ (Figura 2C) e panículas maduras $\mathrm{m}^{-2}$ (Figura 2D), a análise de número de panículas imaturas faz-se necessária (Figura 2E). Assim, constatou-se que o número de panículas maduras $\mathrm{m}^{-2}$ foi afetado com menor intensidade com 1 e 5 plantas $\mathrm{m}^{-2}$, em comparação às demais densidades. Esse resultado pode ser explicado da seguinte forma: como o número total de panículas $\mathrm{m}^{-2}$ foi intensamente reduzido, ou seja, de mais de 300 para 119, todas as panículas formadas nas densidades de 1 e 5 plantas foram diferenciadas na mesma época, em função da menor competição. 
Contudo, nessa condição, apesar de não ter ocorrido interação dos fatores para número de panículas imaturas (Figura 2E), à medida que aumentou o período de convivência, ocorreu incremento desta até próximo de $40 \mathrm{DAE}$, como forma de sobrevivência da planta de arroz. Esse aumento, provavelmente, foi decorrente de panículas provenientes de perfilhos de ordem elevada, que a planta de arroz emitiu como forma de sobrevivência, as quais não estavam maduras no momento da colheita. Com o passar da convivência, a competição foi aumentando, ocorrendo assim degeneração desses perfilhos e até dos primórdios das panículas provenientes desses perfilhos, o que explica a queda após os $40 \mathrm{DAE}$.

Galon et al. (2007) observaram que, à medida que a população, a massa seca aérea, a cobertura do solo e a área foliar da planta daninha aumentam, ocorre redução brusca na produtividade de grãos do arroz, podendo chegar até mesmo a $100 \%$ em altas infestações, quando nenhum controle for efetuado.

A porcentagem de colmos férteis foi significativamente reduzida com o período de convivência (Figura 2F). Esse resultado explica a redução que ocorreu quanto ao número de panículas maduras $\mathrm{m}^{-2}$ (Figura 2D), que, também, foi decorrente da menor transformação das gemas vegetativas em reprodutivas dos colmos que resultaram nessa categoria de panículas. O capim-marmelada, por possuir o metabolismo $\mathrm{C}_{4}$, é altamente competitivo durante o verão, tendo elevada capacidade de extração de recursos naturais do ambiente para realizar processos essenciais, como a fotossíntese (Taiz \& Zeiger, 2004). Pelo fato de o arroz ser planta $\mathrm{C}_{3}$ cultivada no verão, o capim-marmelada é normalmente beneficiado pelo ambiente em termos competitivos.

Souza et al. (2006), estudando o efeito de $B$. decumbens no desenvolvimento do arroz, demonstraram a redução do crescimento desta devido à menor absorção de $\mathrm{N}$. Como o número de panículas está relacionado com o de perfilhos, os quais são definidos entre $14 \mathrm{e}$ 42 dias após a emergência (Stansel, 1975), e está intimamente ligado ao fornecimento de $\mathrm{N}$ (Souza et al., 2006), é de se esperar que haja prejuizo na produtividade pela competição das plantas daninhas com a cultura de arroz e que ela seja minimizada nessa fase - denominada período crítico de competição. Silva \& Durigan (2009) verificaram que a comunidade infestante reduziu o perfilhamento do arroz, levando a um menor número de panículas por unidade de área. Burga $\&$ Tozani (1980) verificaram que essa queda, somada ao menor peso de grãos por panícula, refletiu em redução da produtividade de grãos da ordem de 56 e $71 \%$, em baixas e altas taxas de infestação, respectivamente.

Os números de espiguetas totais (Figura 3A), granadas (Figura 3B) e chochas (Figura 3C) por panícula foram afetados significativamente pela interação entre os fatores. Observa-se que a redução provocada pela densidade de 90 plantas $\mathrm{m}^{-2}$ para números de espiguetas totais e granadas foi mais intensa, quando comparada com as demais densidades. Isso está de acordo com os resultados relatados por Burga \& Tozani (1980), que verificaram redução da produtividade de grãos de arroz devido à competição das plantas daninhas, ocasionada principalmente pela diminuição do número de espiguetas totais por panícula.

O número de espiguetas granadas não foi alterado pela densidade de 1 planta $\mathrm{m}^{-2}$ (Figura 3B). As demais densidades reduziram significativamente os valores dessa variável, o que é explicado, em parte, pela redução do número de espiguetas totais por panícula. Uma outra variável que explica a redução do número de espiguetas granadas e espiguetas chochas por panícula é a fertilidade delas (Figura 3D). Analisando os resultados, verifica-se que não houve efeito das densidades de $1,5 \mathrm{e}$ 25 plantas $\mathrm{m}^{-2}$, ou seja, do estádio do emborrachamento até cinco dias após o florescimento, a competição provocada por essas densidades de $B$. plantaginea não interferiram na formação dos gametas (meiose), na polinização, na fecundação e no início de enchimento dos grãos - eventos esses que interferiu na fertilidade das espiguetas. Essa hipótese ajuda a explicar a redução do número de espiguetas totais, granadas e chochas verificadas nas densidades de 1,5 e 25 plantas $\mathrm{m}^{-2}$. Na densidade de 90 plantas $\mathrm{m}^{-2}$, verifica-se que houve redução significativa da fertilidade das espiguetas, o que explica a redução mais intensa do número de espiguetas totais, granadas e chochas nesse tratamento. 

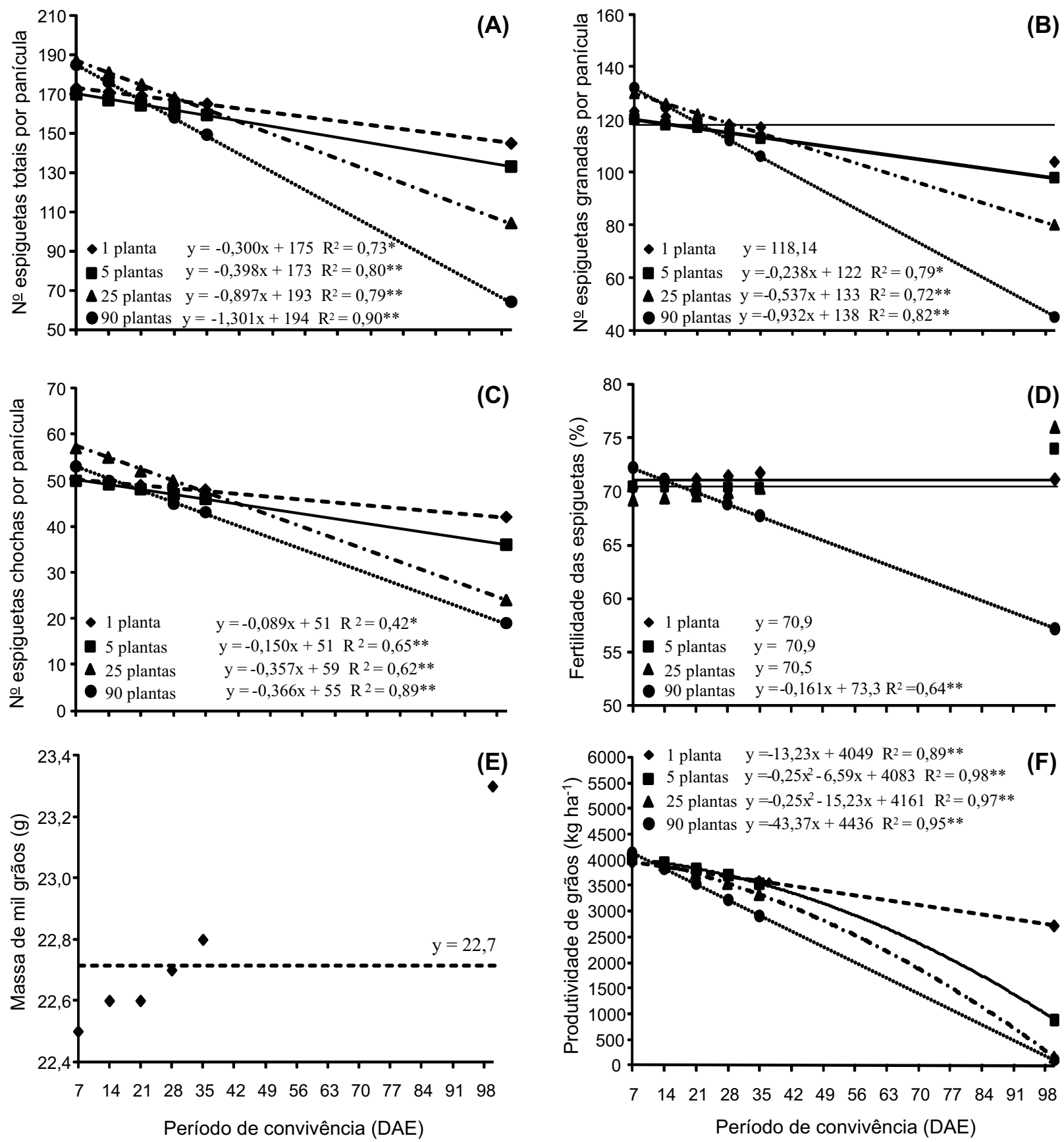

Figura 3 - Número de espiguetas totais por panícula (a), número de espiguetas granadas por panícula (b), número de espiguetas chochas por panícula (c), fertilidade das espiguetas (d), massa de mil grãos (e) e produtividade de grãos (f) do arroz de terras altas, em função da densidade de plantas de B. plantaginea e do período de convivência.

Segundo Fornasieri Filho \& Fornasieri (1993), o número de espiguetas por unidade de área é o determinante primário da produtividade de grãos de arroz. Esse componente pode ser incrementado mediante o aumento do número de panículas $\mathrm{m}^{-2}$ e/ou do número de espiguetas por panícula. Existe, entretanto, um limite para o aumento do número de panículas. Perfilhos adicionais tornam-se improdutivos, ocasionando índice de área foliar (IAF) e crescimento vegetativo excessivo e alta porcentagem de espiguetas vazias. 
A massa de mil grãos (Figura 3E) não foi alterada pelos fatores. Como a planta se ajustou, em termos de desenvolvimento, reduzindo o número de panículas maduras $\mathrm{m}^{-2}$, o número de espiguetas totais por panícula e o de espiguetas granadas por panícula, houve compensação entre fonte e dreno quando esse componente começou a ser definido. Essa definição se dá durante a fase de maturação da cultura, principalmente nos 14 dias após o florescimento, momento em que ocorre o transporte de carboidratos para o preenchimento da casca, e, também, durante as duas semanas que antecedem a antese, quando ocorre a definição do tamanho da casca (Fornasieri Filho \& Fornasieri, 1993).

Os resultados de produtividade de grãos (Figura 3F) acabaram sendo reflexo dos constatados nos componentes da produção, sobretudo os obtidos para número de panículas maduras $\mathrm{m}^{-2}$ e número de espiguetas totais por panícula. Assim, o período de convivência e o aumento do número de plantas de $B$. plantaginea reduziram significativamente a produtividade de grãos, chegando a 164 e $99 \mathrm{~kg} \mathrm{ha}^{-1}$ (decréscimos da ordem de 96 e 98\%,) quando a cultura conviveu, durante todo o ciclo, com a planta daninha nas densidades de 25 e 90 plantas $\mathrm{m}^{2}$, respectivamente.

Silva \& Durigan (2009), ao avaliarem por dois anos consecutivos as relações de interferência entre plantas daninhas e o arroz de terras altas, constataram que a convivência da comunidade infestante durante todo o ciclo da cultura promoveu significativa interferência, resultando em perdas de produtividade de grãos de aproximadamente 95\%.

Fischer et al. (2001), em campo, verificaram que a competição por luz foi o fator crítico da interferência das braquiárias $(B$. brizantha e $B$. decumbens) sobre o arroz de terras altas, com perdas na produtividade de grãos variando de 18 a $55 \%$. Com altas densidades de planta daninha, o dano à cultura ocorre logo após a emergência, ao passo que em densidades menores as injúrias começam a partir do início do perfilhamento (Tozani et al., 1995). Resultados similares foram observados em trabalhos que avaliaram a competitividade entre espécies com algum grau de semelhança (Estorninos Jr. et al., 2005; Fleck et al., 2008).
No entanto, mesmo nas menores densidades, 1 e 5 plantas $\mathrm{m}^{-2}$ (Figura 3F), a convivência por todo o ciclo refletiu em produtividades da ordem de 2.726 e $889 \mathrm{~kg} \mathrm{ha}^{-1}$, em termos percentuais, reduções de 33 e $78 \%$, respectivamente.

Segundo Garrity et al. (1992), o arroz de terras altas não compete bem com as plantas daninhas, a menos que o controle seja precoce e bem realizado. Experimentos conduzidos por Merotto Jr. et al. (2002) indicaram que a presença de plantas daninhas até $15 \mathrm{DAE}$ diminuiu o crescimento do arroz.

Esses relatos são confirmados quando se considera a convivência por até $35 \mathrm{DAE}$ (Figura 3F), em que as reduções na produtividade de grãos foram da ordem de 11,13, 20 e $34 \%$, respectivamente, para as densidades de $1,5,25$ e 90 plantas $\mathrm{m}^{-2}$.

Esses resultados corroboram os obtidos por Silva \& Durigan (2009), que evidenciaram a necessidade de controle no início de desenvolvimento da cultura, em face do rápido crescimento das plantas daninhas, sobretudo gramineas, e do lento desenvolvimento inicial das plantas de arroz. Enfatizaram ainda a necessidade de intervenções nos primeiros 20 a 30 dias após a emergência da cultura.

Entre outros fatores, a interferência de B. plantaginea na cultura do arroz depende da sua densidade e do seu período de convivência. Em densidades abaixo de 5 plantas $\mathrm{m}^{-2}$ de B. plantaginea, a matointerferência reduziu a produção de grãos da cultura do arroz após o início do perfilhamento. Já com sete dias de competição foi constatada redução de alguns parâmetros avaliados, como: número de colmos por metro quadrado, número de panículas maduras e chochas $\mathrm{m}^{-2}$ e número de espiguetas, evidenciando assim a agressividade de B. plantaginea.

\section{LITERATURA CITADA}

BRASIL. Ministério da Agricultura e Abastecimento e de Reforma Agrária. Regras para análise de sementes. Brasília, DF: SNDA/DNDV/CLAV, 1992. 365 p.

BURGA, C. A.; TOZANI, R. Competição de plantas daninhas com a cultura do arroz de sequeiro (Oryza sativa). Agronomia, v. 33, n. 1, p. 23-34, 1980. 
CHRISTOFFOLETI, P. J.; PASSINI, T. Manejo integrado de plantas daninhas na cultura do feijão. In: FANCELLI, A. L.; DOURADO NETO, D. Feijão irrigado: estratégias básicas de manejo. Piracicaba: LPV/ESALQ/USP, 1999. p. 80-97.

\section{COMPANHIA NACIONAL DE ABASTECIMENTO -} CONAB. Levantamento de grãos: Safra 2009/2010.

Disponível em: <http://www.conab.gov.br>. Acesso em: 27 jan. 2011.

\section{EMPRESA BRASILEIRA DE PESQUISA}

AGROPECUÁRIA - EMBRAPA. Centro Nacional de Pesquisa de Solos. Sistema brasileiro de classificação de solos. 2.ed. Rio de Janeiro: 2006. 306 p.

ESTORNINOS JR., L. E. et al. Rice and red rice interference. II. Rice response to population densities of three red rice (Oryza sativa) ecotypes. Weed Sci., v. 53, n. 5, p. 683-689, 2005.

FISCHER, A. J. et al. Competitiveness of semidwarf upland rice cultivars against palisadegrass (Brachiaria brizantha) and sinalgrass (Brachiaria decumbens). Agron. J., v. 93, n. 5, p. 967-973, 2001.

FLECK, N. G. et al. Competitividade relativa entre cultivares de arroz irrigado e biótipo de arroz vermelho.

Planta Daninha, v. 26, n. 1, p. 101-111, 2008.

FORNASIERI FILHO, D.; FORNASIERI, J. L. Manual da cultura do arroz. Jaboticabal, SP: FUNEP, 1993. 221 p.

GALON, L. et al. Estimativa das perdas de produtividade de grãos em cultivares de arroz (Oryza sativa) pela interferência do capim-arroz (Echinochloa spp.). Planta Daninha, v. 25, n. 4, p. 697-707, 2007.

GARRITY, D. P. et al. Differential weed suppression ability in upland rice cultivars. Agron. J., v. 84, n. 4, p. 586-591, 1992.

MEROTTO Jr., A. et al. Interferência das plantas daninhas sobre o desenvolvimento inicial de plantas de soja e arroz através da qualidade da luz. Planta Daninha, v. 20, n. 1, p. 9-16, 2002.
OERKE, E. C.; DEHNE, H. W. Safeguarding production losses in major crops and the role of crop protection. Crop Protec., v. 23, n. 4, p. 275-285, 2004.

PITELLI, R. A Interferência de plantas daninhas em culturas agrícolas. Inf. Agropec., v. 11, n. 129, p. 16-27, 1985.

RADOSEVICH, S. R.; HOLT, J.; GHERSA, C. Weed ecology: implications for management. 2.ed. New York: John Wiley \& Sons, 1997. 589 p.

RAIJ, B. van.; QUAGGIO, J. A. Métodos de análise de solo para fins de fertilidade. Campinas, Instituto Agronômico de Campinas, 1983. p. 1-31. (Boletim Técnico, 81)

SILVA, M. R. M.; DURIGAN, J. C. Períodos de interferência das plantas daninhas na cultura do arroz de terras altas. II cultivar Caiapó. Bragantia, v. 68, n. 2, p. 373-379, 2009.

SOUZA, L. S. et al. Efeito alelopático de capim-braquiária (Brachiaria decumbens) sobre o crescimento inicial de sete espécies de plantas cultivadas. Planta Daninha, v. 24, n. 4, p. 657-668, 2006.

STANSEL, J. W. The rice plant: its development and yield. In: Texas Agricultural Experiment Station. College Station: Six decades of rice research in Texas, 1975. p. 9-21 (Research Monograph, 4).

TAIZ, L.; ZEIGER, E. Fisiologia vegetal. 3.ed. Porto Alegre: Artmed, 2004. 719 p.

THEISEN, G.; VIDAL, R. A.; FLECK, N. G. Redução da infestação de Brachiaria plantaginea em soja pela cobertura do solo com palha de aveia preta. Pesq. Agropec. Bras., v. 35, n. 4, p. 753-756, 2000.

TOZANI, R. et al. Interferência de Cyperus rotundus em arroz de sequeiro conduzido em três densidades e dois espaçamentos. Planta Daninha, v. 13, n. 1, p. 87-97, 1995.

VOLL, E.; GAZZIERO, D. L. P.; KARAM, D. Dinâmica de populações de Brachiaria plantaginea (Link) Hitchc. sob manejos de solo e de herbicidas. I. Sobrevivência. Pesq.

Agropec. Bras., v. 30, n. 12, p. 1387-1396, 1995. 